\title{
PROS Y CONTRAS DE LA POLÍTICA DE COOPERACIÓN ESPAÑOLA. LA LEY DE COOPERACIÓN INTERNACIONAL PARA EL DESARROLLO A EXAMEN
}

\section{ALFREDO HIDALGO LAVIÉ}

Profesor de Servicios Sociales y Política Social. Escuela Universitaria de Trabajo Social de Jerez. Universidad de Cádiz.

\section{INTRODUCCIÓN}

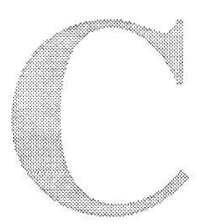

on motivo de la celebración del I Congreso Andaluz de Escuelas de Trabajo Social celebrado en Málaga los días 21 y 22 de mayo de 1998, tuve la ocasión de presentar una comunicación bajo el título «Una valoración sobre la Ley española de Cooperación Internacional para el Desarrollo».1 en la que expuse en conocimiento de la audiencia los apartados más relevantes de la misma, las posturas políticas sostenidas por los distintos grupos parlamentarios de la cámara del Congreso de los Diputados, así como los contenidos más sobresalientes del proyecto de ley introducido por el gobierno del Partido Popular y los argumentos esgrimidos por la Plataforma 0 '7 a este respecto. Esta comunicación, nutrida de comentarios, análisis y valoraciones que incorporé a título propio, finalizaba con una seria advertencia que reproduzco textualmente a continuación: «afirmaba el diputado de Convergència $i$ Uniò, el señor Recorder $i$ Miralles, que no todos los grupos parlamentarios se han tomado con el mismo interés el debate sobre esta ley y no tenía ninguna esperanza de que sus palabras trascendieran más allá de su tribuna. Pues bien, gracias a la admisión de esta comunicación por los organizadores de este Congreso, podemos recordar que la Plataforma 0'7 ha subrayado que la presión de este grupo parlamentario ha sido no sólo necesaria, sino vital». Detrás de este enunciado se ocultaba un temor no injustificado como ha venido a demostrar el posterior desarrollo legislativo de esta materia. La mayoría absoluta que

Actas del I Congreso Andaluz de Escuelas de Trabajo Social, "El Trabajo Social en los Servicios Sociales y en la Política Social: reto para el tercer milenio», Escuela Universitaria de Trabajo Social de Málaga, 1999. 
detenta el Partido Popular, y como así consta en el Diario de Sesiones del Senado, trastocó substancialmente ciertos contenidos del proyecto de ley aprobado por el Congreso de los Diputados, quebrando, pues, de este modo el elogiable consenso alcanzado entre todas las fuerzas políticas del arco parlamentario y los agentes sociales más involucrados en este ámbito.

Una vez más, el apoyo del grupo parlamentario de Convergència $i$ Unió contribuyó a enderezar las posturas adoptadas en la cámara del Congreso, siendo rechazadas las enmiendas más sobresalientes del Senado y la actual Ley de Cortes 23/1998, de 7 de julio, de Cooperación Internacional para el Desarrollo, publicada en el Boletín Oficial del Estado un día después (núm.162), renaciendo del consenso político, cuya satisfacción no ha dudado en hacer pública, incluso, la Coordinadora de ONGD y la Plataforma 0'7.

Como a continuación tendremos ocasión de comprobar, esta satisfacción es resultado de numerosos esfuerzos realizados desde aquellos emblemáticos días de los meses de septiembre a noviembre de 1994, fecha en la que se organizó la renombrada «Acampada de la Solidaridad» en el Paseo de la Castellana de Madrid, que condujo a la reproducción de este modelo de movilizaciones a lo largo y ancho del Estado, creándose aproximadamente cuarenta acampadas simultáneas; todo un fenómeno social teniendo en cuenta que sólo un reducido grupo de ciudadanos, sin dinero y con escasas infraestructuras organizativas, alcanzaron tanto poder de convocatoria, el cual es, incluso, mencionado indirectamente en el apartado II de la Ley ya en vigor, al enunciar: «el aumento de los fondos dedicados a cooperación, muestra la solidaridad de España y en buena medida propiciado por la creciente sensibilización del conjunto de la sociedad...».

Ciertamente, y como es natural en todo proceso consensual, las reivindicaciones individuales de cada grupo político y de presión no han podido ser enteramente satisfechas, como así consta en el comunicado de prensa de la Plataforma 0'7, pero ya es en sí relevante que una norma con rango de ley tan esperada y solicitada haya alcanzado tan notable capacidad de integración. Es, pues, todo un hito para la historia de la cooperación española en materia de desarrollo la aprobación y entrada en vigor de esta ley. Bastaría recordar, con el ánimo de subrayar y resaltar su relevancia, que hasta el momento presente la cooperación efectuada por nuestro país con los países en vías de desarrollo sólo disponía de reales decretos, relacionados más con la creación de determinados organismos del Ministerio de Asuntos Exteriores que con la naturaleza misma de la cooperación, siendo éstos, por consiguiente, el más alto rango de las normas que regían nuestra ayuda para el desarro- 
llo. Afortunadamente, hoy día puede hablarse ya, y con propiedad, de la existencia de un marco legal que regula las acciones y actividades relacionadas con la cooperación española, debiéndose entender ésta como "el conjunto de recursos y capacidades que España pone a disposición de los países en vías de desarrollo, con el fin de facilitar e impulsar su progreso económico y social, y para contribuir a la erradicación de la pobreza en el mundo en todas sus manifestaciones», impulsando a su vez «...la defensa y protección de los derechos humanos y las libertades fundamentales, las necesidades de bienestar económico y social, la sostenibilidad y regeneración del medio ambiente (y)...la plena consolidación de sus instituciones democráticas y su inserción en la economía internacional» (art.1. de la ley de 1998) ${ }^{2}$.

\section{UNA PANORÁMICA GENERAL DE LA EVOLUCIÓN DE LA COOPERACIÓN ESPAÑOLA PARA EL DESARROLLO.}

Una ligera endoscopia sobre las repercusiones y evolución de las políticas llevadas a cabo en cooperación para el desarrollo en los países de nuestro entorno occidental nos permite sostener, sin lugar a dudas, una primera afirmación concluyente sobre el modelo de nuestro país a este respecto ${ }^{3}$.

Cuando en 1961 se crea en los Estados Unidos la Agencia para el Desarrollo Internacional y en 1962 su equivalente en Suecia (en adelante estos organismos se reproducen por doquier por toda Europa),

2 El elevado número de enmiendas presentadas por los diversos partidos políticos con representación parlamentaria al inicial proyecto gubernamental sobre la ley de cooperación permite afirmar, una vez más y como de este modo así ha sido reconocido por los portavoces de las distintas fuerzas políticas, las mejoras introducidas al proyecto de ley fruto del consenso y de la negociación entre los miembros de la clase política de nuestro país. Prueba de ello, es la modificación de este primer artículo, bajo la rúbrica «Objeto de la ley y ámbito de actuación» al sustituir el siguiente enunciado «...con el propósito fundamental de estimular el desarrollo económico y el bienestar social de sus habitantes, de forma que esos países puedan instrumentar un sistema económico y social estable en un plazo razonable» por el contenido anteriormente recogido casi en su integridad.

3 Las políticas de cooperación para el desarrollo devienen, a mi modo de ver, una variable verosímil para proceder a la elaboración de una nueva tipología sobre los Estados de Bienestar. A este respecto, puede consultarse Alfredo Hidalgo Lavié, "La dimensión internacional del Estado de Bienestar: las politicas de cooperación para el desarrollo», en Servicios Sociales y Política Social, Revista de Trabajo Social, Consejo General de Colegios Oficiales de Diplomados en Trabajo Social, n. ${ }^{\circ}$ 47, Madrid, 1999, pp.111126. 
España es aún un país atrasado social, cultural y políticamente, inmerso en un régimen autoritario, aislado y reticente ante toda influencia exterior. Un legado, tras cuarenta años de régimen franquista, que encuentra un exponente ilustrativo en el hecho de que en 1977 es considerado aún como país receptor de ayuda por la institución del Banco Mundial e incluso en 1981, todavía, figura como país en vías de desarrollo por el Fondo Monetario Internacional. Por consiguiente, económicamente también, nuestro país forma parte del mundo en desarrollo. Este aislamiento junto a la ausencia de infraestructuras necesarias en todos los ámbitos, pero particularmente en el económico (no olvidemos la elevada tasa de desempleo que nos coloca en el ranking de los miembros de la Unión Europea), van a explicar, en gran medida, la naturaleza de nuestras políticas de cooperación y la utilización de las mismas como yacimiento de canalización de excedentes comerciales, creación de empleo $y$, en definitiva, posibilidades de crecimiento económico para nuestras empresas. Las denuncias de los colectivos sociales sobre la utilización desmesurada de los créditos del Fondo de Ayuda para el Desarrollo (FAD), así como las observaciones manifestadas por el Comité de Ayuda al Desarrollo (CAD) y recogidas en el Informe de 1994 de la OCDE, según el cual «España es el país cuyo programa de ayuda presenta el carácter más comercial y se coloca en el segundo puesto de los miembros del CAD por la dureza de las condiciones que aplica» ${ }^{4}$, encuentran su raíz en este aislamiento y lamentable atraso.

No obstante, tímidas realizaciones fueron llevadas a cabo durante esos difíciles años que tal vez, a modo de precedentes, pueden ser consideradas en la breve historia de la política internacional española para el desarrollo. Así, en 1945 se crea, en el seno del Ministerio de Asuntos Exteriores, la Dirección General de Relaciones Culturales con el objetivo de difundir la cultura y lengua españolas en el extranjero, primordialmente América Latina, y fomentar los intercambios culturales, por lo que, para su coordinación, se estableció el Instituto de Cultura Hispánica en 1947 (a partir de 1979, Instituto de Cooperación Iberoamericana). Sin embargo, y ciertamente, mal podemos remitirnos a este instituto como precedente propiamente dicho dado que su único objetivo consistía en conservar unos vínculos espirituales con la comunidad de habla hispana, muy diferentes de las finalidades de las Agencias anteriormente mencionadas y la Resolución adoptada por la Asamblea General de las Naciones Unidas en la misma década.

Más correcto es tomar en consideración como referente, y más ajustado a una auténtica concepción de política de cooperación para el

«Série des examens en matière de coopération pour le développement, Espagne», OCDE, $\mathrm{n}^{\circ} 3,1994, \mathrm{p} .8$. 
desarrollo, el año 1976, fecha de la creación del Fondo de Ayuda para el Desarrollo, ${ }^{5}$ que incorpora a nuestro país al grupo de países donantes (paradójicamente, cuando era receptor de ayuda) con el objeto de otorgar créditos ligados a la adquisición de bienes y servicios españoles.

A partir de esta fecha, la política de cooperación española penetra en una espiral de realizaciones que actualizan las exiguas realizaciones llevadas a cabo en este ámbito de la política exterior y la colocan, grosso modo, al nivel de la realizadas por los Estados de nuestro entorno. De este modo, en 1980 España se adhiere al Convenio de Ayuda Alimentaria, un año después a la Reserva Alimentaria Internacional de Emergencia de la FAO y, finalmente, a mediados de los años ochenta, se establecen las primeras instituciones y organismos españoles consagrados para este fin:

- en 1985, se crea la Secretaría de Estado de Cooperación Internacional y para Iberoamérica (SECIPI) con la función de dirigir, programar, controlar y evaluar las actividades en materia de cooperación adscrita al Ministerio de Asuntos Exteriores. ${ }^{6}$

- en 1986, y con la función de «someter a la aprobación del gobierno, a través del Ministerio de Asuntos Exteriores, dentro del primer semestre de cada año natural, y previamente a la presentación en Consejo de Ministros del anteproyecto de Ley de Presupuestos Generales del Estado, la propuesta del Plan Anual de Cooperación Internacional del ejercicio siguiente, así como de los recursos presupuestados necesarios para su buen fin ${ }^{7}$, se establece la Comisión Interministerial de Cooperación Internacional.

Debe ser subrayado claramente que las críticas de los colectivos sociales y la observaciones emitidas por el CAD sobre los créditos FAD no exigen su eliminación, pues ciertamente otros muchos países utilizan este modelo de crédito para operaciones similares, sino sobre su utilización desmesurada que pone en cuestionamiento la realización de una auténtica política de cooperación. Aunque más adelante haré referencia nuevamente a este punto, recordaré que según este mismo Informe del CAD, el aumento del volumen experimentado en Ayuda Oficial para el Desarrollo en nuestro país se debe fundamentalmente al incremento equivalente en los créditos FAD otorgados, retrocediendo las donaciones bilaterales y las contribuciones a los organismos multilaterales.

- En 1996, se procedió a modificar la estructura orgánica del Ministerio de Asuntos Exteriores. Según el art. 10 del Real Decreto 1881/1996, de 2 de agosto, de estructura orgánica básica del Ministerio de Asuntos Exteriores, corresponde a la SECIPI asistir "al Ministerio de Asuntos Exteriores en la formulación y ejecución de la política de Cooperación para el Desarrollo y de las relaciones económicas, culturales y cientificas, coordinando las actividades que en esas áreas tengan atribuidas otros órganos de la Administración General del Estado...».

7 Art.4.1. del Real Decreto 451/1986, de 21 de febrero, por el que se crea la Comisión Interministerial de Cooperación Internacional. 
- Y, finalmente, en 1988 se crea la Agencia Española de Cooperación Internacional como organismo autónomo de la Administración del Estado, adscrito también al Ministerio de Asuntos Exteriores a través de la SECIPI, con la finalidad de poner en marcha y gestionar los proyectos y programas de ayuda internacional al desarrollo ${ }^{8}$.

No obstante, a pesar de esta aparente concentración de actividades en materia de cooperación para el desarrollo en torno al Ministerio de Asuntos Exteriores, este departamento ministerial no ha monopolizado, ni siquiera con la nueva Ley recién debutada, todas las competencias en este ámbito. Más aún, la inexperiencia española en este campo, como consecuencia del retraso ya resaltado, muestra unas incongruencias difícilmente aceptables, tales como que el Ministerio de Trabajo fue el pionero en cooperación internacional, actividad que posteriormente, en 1965, fue asumida igualmente por otros departamentos, como Sanidad, Obras Públicas, Agricultura, Transportes, Turismo y Comunicaciones. Por ende, ni siquiera hoy día, existe un órgano administrativo que centralice toda la cooperación española (distribuyéndose ésta entre un bien nutrido número de departamentos ministeriales, teniendo que contar además, como poco más adelante señalaré, con la denominada «cooperación descentralizada $»^{9}$ ).

Desde un punto de vista normativo, ya ha sido comentada la ausencia de una ley que hubiese regulado el régimen jurídico de la política española de cooperación internacional. No obstante, se ha hecho mención a los decretos leyes que, como se ha podido comprobar, han dado lugar al establecimiento de organismos indispensables para la planificación, coordinación, evaluación y control de la misma. Por consiguiente, y como veremos en el capítulo siguiente, no ha existido ni una sola norma que determinase los contenidos de la política a seguir. Es muy probable, que esta ausencia, motivada por un incumplimiento político expresado en varias ocasiones, pueda explicar las «anomalías», insuficiencias y marcado alejamiento de las líneas generales de las políticas cuencia de la refundición del Instituto de Cooperación Iberoamericana ya citado y el Instituto Hispano-Arabe de Cultura. Posteriormente, por medio del Real Decreto $1141 /$ 1996, de 2 de mayo se remodela sus órganos de gobierno con el fin de agilizar y hacer más operativo su funcionamiento, tal y como consta en las primeras líneas de esta mencionada norma.

9 El art. 18 de la recién estrenada Ley $23 / 1998$ de 7 de julio determina que «los Ministerios que realicen en materias de cooperación internacional para el desarrollo serán responsables de la ejecuciôn de los programas, proyectos y acciones dentro del ámbito de sus competencias». 
aplicadas por los Estados occidentales. Sin embargo, esta importante ausencia, reclamada incluso por el CAD, no ha impedido la elaboración de recomendaciones por parte de las cámaras que constituyen las Cortes Generales. Así, la Moción sobre Cooperación Internacional de España para el Desarrollo aprobada por el Senado en 1984 ya incluía, entre otras recomendaciones, una indispensable unidad de acción exterior, la necesidad de regirse por una ley, la creación de un órgano planificador y coordinador, el principio inspirador sobre el que tiene que sostener toda política de cooperación (la responsabilidad solidaria en todos los ámbitos) y cierto toque de atención a la orientación comercial de las políticas aplicadas a través de los créditos FAD.

Tres años más tarde, en 1987, el Consejo de Ministros acuerda «las líneas directrices de la política de cooperación al desarrollo» en donde se reafirma el punto de fricción que ha dado lugar a las críticas vertidas sobre la naturaleza de nuestra cooperación al exponer en los Principios Rectores que la cooperación «no debilita el crecimiento económico nacional. Los recursos dedicados... no son restados al crecimiento de nuestra economía. Por el contrario, la Cooperación puede y debe contribuir directamente a ese crecimiento y a la creación de empleo ${ }^{10}$, comprometiéndose, al mismo tiempo, a dedicar el 0'7\% del PIB a la ayuda al desarrollo, anticipando que en 1992 la Ayuda Oficial al Desarrollo de nuestro país alcanzaría la mitad de lo que dedican en concepto de ayuda los países del $\mathrm{CAD}^{11}$.

En 1992, el Informe del Congreso de los Diputados arrojó una estela de esperanza al reconsiderar la polémica suscitada por la utilización de los créditos ligados (FAD), pues en dicho Informe, aunque se reconoce y admite nuevamente «...que estos créditos también constituyen indirectamente ayudas a nuestras exportaciones de bienes y servicios» añade asimismo que «no debe tratarse de incluir dentro de la AOD lo que en realidad responde exclusivamente a la lógica comercial» ${ }^{12}$, recordando, a su vez, el incumplimiento del volumen de la ayuda y esta-

10 Principios Rectores, Acuerdo del Consejo de Ministros de 18 de diciembre de 1987, sobre las Líneas Directrices de la Política de Cooperación al Desarrollo.

"Según datos de la OCDE, en 1992 la media de las inversiones de los países miembros del CAD alcanzó el 0'33\% del PNB. España, con sus 1.518 millones de dólares, logró sólo un $0^{\prime} 27 \%$, sólo por delante de Luxemburgo y Nueva Zelanda con $0^{\prime} 26 \%$ respectivamente, Estados Unidos con 0'26\% y en último lugar Irlanda con $0^{\prime} 16 \%$.

12 Informe del Congreso de los Diputados sobre los objetivos y las líneas generales de la política española de cooperación y ayuda al desarrollo, de 30 de junio de 1992, el cual fue elaborado por la Comisión de Asuntos Exteriores del Congreso de los Diputados y cuyo dictamen fue ratificado por unanimidad ante el pleno de la cámara en su sesión de 26 de noviembre. 
bleciendo para el año 2000 el logro del $017 \%$ y para 1995 el $0^{\prime} 35 \%{ }^{13}$.

Por último, en 1994, el Senado emitió una serie de recomendaciones sumamente importantes, tales como el carácter imprescindible de la participación de los órganos competentes del Ministerio de Asuntos Exteriores en el proceso de selección de proyectos susceptibles de la concesión de un crédito FAD, para identificar y asegurar que se tiene en cuenta los criterios propios de la ayuda al desarrollo, así como la modificación y adecuación «...de la legislación que regula los créditos FAD, para adecuarla al nuevo marco institucional desarrollado en los últimos años, a la normativa del CAD y al Consenso OCDE...» ${ }^{14}$.

Una segunda conclusión, pues, a considerar tras toda esta exposición de acontecimientos nos debe conducir a la siguiente proximidad objetiva.

Por un lado, no todas las recomendaciones emitidas por las Cámaras han sido incumplidas. Ha existido, pues, una voluntad política cierta en modernizar, ¿o habría que decir crear desde cero?, toda una infraestructura administrativa, y junto a ella normativa, en materia de política de cooperación, consolidándose, por ende, un marco institucional inexistente tras la recuperación de las libertades, aunque, obviamente, no con la firmeza ni con la demagogia política utilizada frecuentemente, especialmente a la hora de comprometerse con unos logros que no van a cumplirse, que la sociedad civil hubiese querido ${ }^{15}$.

\section{ANÁLISIS DE LAS ADJUDICACIONES REALIZADAS EN MATERIA DE COOPERACIÓN PARA EL DESARROLLO.}

Otro de los importantes logros realizados en estas dos últimas décadas, a pesar de los lustros de retraso repetidamente esgrimidos ya en párrafos anteriores, reside en el volumen neto de las partidas presu-

13 Esta previsión tampoco fue alcanzada, pues frente al $0227 \%$ de media de los países del CAD, España invirtió sólo 0'24\% de su PNB (0'04\% menos que en 1994).

14 Recomendaciones del Senado contenidas en el Informe de la Política Española de Cooperación para el Desarrollo, de 17 de noviembre de 1994.

is Como veremos a continuación, y en opinión de la OCDE, nuestro país ha vinculado su ayuda a la adquisición y servicios del país donante, por lo que puede afirmarse que se ha estimado mucho más relevante la venta de productos nacionales que las necesidades del país receptor. Es loable, pues, el reconocimiento público del portavoz del grupo socialista, Estrella Pedrola, al admitir que, ya durante la etapa socialista, la política de cooperación se proveía de fondos para ayuda a la exportación, aunque «siendo éstos así en su inmensa mayoría..., se llamaban de ayuda al desarrollo", Diario de Sesiones del Congreso de los Diputados, n. ${ }^{\circ} 153,23$ de abril de 1998, pág. 8172. 
puestarias destinadas a política de cooperación. De los 237 millones de dólares corrientes en 1981 a los 1.305 millones de 1994, casi seis veces más de lo presupuestado a comienzos de este período. Sin embargo, este crecimiento no ha sido sostenido hasta 1986, año a partir del cual las cifras van incrementándose paulatinamente en los años sucesivos, remontando la inestabilidad precedente que llegó a alcanzar la ridícula cantidad de 70 millones en 1983.

$\begin{array}{rr}\text { Año } & \text { AOD } \\ 1981 & 237 \\ 1982 & 233 \\ 1983 & 70 \\ 1984 & 144 \\ 1985 & 169 \\ 1986 & 203 \\ 1987 & 232 \\ 1988 & 248 \\ 1989 & 541 \\ 1990 & 965 \\ 1991 & 1.262 \\ 1992 & 1.518 \\ 1993 & 1.304 \\ 1994 & 1.305\end{array}$

Fuente: OCDE.

Sin embargo, el volumen de la ayuda expresada en porcentaje del Producto Nacional Bruto revela otra lectura bien diferente y, sobre todo, si se tiene como punto de referencia la media de las aportaciones de los países del CAD. Primeramente, las partidas presupuestarias españolas han sido, en general, muy reducidas, por lo que el incremento realizado en los últimos años, que ha permitido acercar nuestro porcentaje del PNB a la media de los miembros del CAD, aunque relevante, no obstante, es deslucido por las pequeñas partidas iniciales. En segundo lugar, nuestro país, en todo este período, no ha alcanzado jamás la media de los países del CAD, produciéndose el mayor distanciamiento a partir de 1983 , con un $0{ }^{\prime} 04 \%$ frente al 0'34\%, para remontar posteriormente a partir de 1989, pero cuyo acercamiento a la media de los países de la OCDE es más resultado de la disminución o parálisis de las partidas presupuestarias de_éstos (0'32 y 0’33\% durante los años 1989, 1990, 1991 y 1992) que de un incremento moderado y sucesivo de la ayuda española. 


$\begin{array}{lcc}\text { año } & \text { \% del PNB español } & \text { \% del PNB (total CAD) } \\ 1981 & 0^{\prime} 13 & 0^{\prime} 32 \\ 1982 & 0^{\prime} 13 & 0^{\prime} 36 \\ 1983 & 0^{\prime} 04 & 0^{\prime} 34 \\ 1984 & 0^{\prime} 08 & 0^{\prime} 34 \\ 1985 & 0^{\prime} 10 & 0^{\prime} 33 \\ 1986 & 0^{\prime} 09 & 0^{\prime} 34 \\ 1987 & 0^{\prime} 08 & 0^{\prime} 33 \\ 1988 & 0^{\prime} 07 & 0^{\prime} 34 \\ 1989 & 0^{\prime} 14 & 0^{\prime} 32 \\ 1990 & 0^{\prime} 20 & 0^{\prime} 33 \\ 1991 & 0^{\prime} 24 & 0^{\prime} 33 \\ 1992 & 0^{\prime} 27 & 0^{\prime} 33 \\ 1993 & 0^{\prime} 28 & 0^{\prime} 30 \\ 1994 & 0^{\prime} 28 & 0^{\prime} 30\end{array}$

Fuente: OCDE.

Tan importante como el volumen de la ayuda es la calidad de la misma, manifestada en la distribución de partidas bilaterales/multilaterales como por sectores de aplicación.

Las primeras hacen referencia a los compromisos que adopta nuestro país directamente con los países en vías de desarrollo, mientras que las ayudas multilaterales son aquellas que comprenden cuotas y atribuciones a organismos internacionales, ya financieros (como el Banco Mundial o el FMI), o no (como Naciones Unidas, UNICEF, FAO), y las destinadas directamente al presupuesto comunitario, las cuales experimentan un crecimiento considerable durante los años ochenta, pero descienden a partir de comienzos de la década de los noventa. Nuestro país, a diferencia de otros miembros del CAD, ha dado un especial énfasis a las sumas dirigidas tanto al Fondo Europeo al Desarrollo como para el conjunto del presupuesto de la política de la Unión, mientras que la mayoría de los países del CAD han venido repartiendo más proporcionalmente sus recursos entre todos los organismos internacionales. Obviamente, el peso adquirido por la cooperación de tipo multilateral es producto de los compromisos contraídos por la Administración española en aras de la normalización de nuestra presencia en los foros internacionales. Muchos especialistas en cooperación para el desarrollo han venido enfatizando desde hace ya bastante tiempo la necesidad de que nuestra política en esta área incremente sustancialmente sus cuotas en ayuda multilateral con el objeto de imprimir en ella, subrayan, una cooperación de mayor «calidad», dado que ésta subordina los intereses nacionales (propios de las ayudas bilaterales) a los objetivos establecidos por los organismos internacionales, de mayor contenido general. 


\begin{tabular}{|c|c|c|}
\hline Año & Bilateral & Multilatera \\
\hline 1981 & $86 ' 5 \%$ & $13,5 \%$ \\
\hline 1982 & $70^{\prime} 4 \%$ & $29^{\circ} 6 \%$ \\
\hline 1983 & $78.8 \%$ & $19 \cdot 7 \%$ \\
\hline 1984 & $75^{\prime} 7 \%$ & $23 \% \%$ \\
\hline 1985 & $76^{\prime} 3 \%$ & $23.6 \%$ \\
\hline 1986 & $29^{\prime} 0 \%$ & $71^{\prime} 4 \%$ \\
\hline 1987 & $49^{\prime} 1 \%$ & $50,8 \%$ \\
\hline 1988 & $63^{\prime} 7 \%$ & $36.9 \%$ \\
\hline 1989 & $48^{\prime} 9 \%$ & $51^{\prime} 2 \%$ \\
\hline 1990 & $65^{\prime} 6 \%$ & $34: 4 \%$ \\
\hline 1991 & $60^{\prime} 3 \%$ & $39 \%$ \\
\hline 1992 & $72^{\prime} 4 \%$ & $27^{\prime} 6 \%$ \\
\hline 1993 & $71 \% 7 \%$ & $29 \cdot 3 \%$ \\
\hline 1994 & $65^{\prime} 4 \%$ & $34 \% \%$ \\
\hline
\end{tabular}

Fuente: OCDE.

Se observará, en función de los datos proporcionados por la OCDE, que sólo en 1986, 1987 y 1989 las partidas destinadas a la ayuda multilateral superan, particularmente en 1986 con un 71'4\% del total de la AOD, a las realizadas directamente por las autoridades españolas. En lo que respecta a su composición, y como ya ha sido señalado, la Comunidad Europea es la que más fondos recibe con un 62'97\% de media durante este período (teniendo en consideración, lógicamente, la fecha de ingreso de nuestro país en dichas instituciones), seguidas por las del Banco Mundial (13'97\%), Bancos de Desarrollo Regional $\left(10^{\prime} 76 \%\right)$ y Agencias de Naciones Unidas (8'95\%). En millones de dólares corrientes, la evolución ha sido la siguiente:

$\begin{array}{lccccc} & \text { Com.Eu. } & \text { B.M. } & \text { B.D.R. } & \text { N.U. } & \text { Otras } \\ 1986 & 20 & 52 & 36 & 22 & 15 \\ 1987 & 26 & 34 & 23 & 22 & 12 \\ 1988 & 64 & 9 & 5 & 12 & 2 \\ 1989 & 110 & 107 & 29 & 26 & 4 \\ 1990 & 230 & - & 69 & 28 & 5 \\ 1991 & 318 & 116 & 28 & 28 & 11 \\ 1992 & 343 & 20 & 16 & 35 & 5 \\ 1993 & 281 & 16 & 42 & 22 & 6 \\ 1994 & 334 & 23 & 32 & 37 & 25\end{array}$

Fuente: OCDE.

La ayuda bilateral española ha estado protagonizada por los créditos FAD, los cuales son otorgados por el gobierno español, que libremente elige tanto a los países destinatarios como los programas y criterios para su utilización. Estos tipos de créditos adoptan la forma de ayuda financiera reembolsable, aunque concesional, es decir, ajustada a condiciones financieras más blandas que las que caracterizan las operaciones comerciales ordinarias, pero a su vez ligadas a la adquisición de bienes y servicios españoles, razón por la que los créditos FAD han venido convirtiéndose en un importante instrumento de potenciación de 
la política comercial de nuestro país, no en vano, estos créditos son gestionados directamente por la Dirección General de Política Comercial, adscrita al Ministerio de Comercio y Turismo, y cuyo titular es el Secretario de Estado de dicho Ministerio.

Obviamente, la ayuda bilateral de nuestro país no se agota en esta única vía, pues junto a los créditos $\mathrm{FAD}$, son utilizados otros instrumentos, más acordes con las recomendaciones del CAD, tales como la ayuda alimentaria, la ayuda de emergencia, las subvenciones otorgadas a las ONGD, la asistencia técnica, todas las cuales pueden ser incluidas en un único paquete bajo la rúbrica Ayuda bilateral no reembolsable.

La importancia de estos créditos en el seno de la ayuda bilateral española puede ser constatada de dos modos diferentes.

Por un lado, en función de la importancia de los distintos departamentos ministeriales en relación al reparto de la Ayuda Oficial al Desarrollo. Por ejemplo, en 1995, y según los Planes Anuales de Cooperación Internacional (PACI), el Ministerio de Comercio y Turismo gestionaba nada menos que un $45 \%$ de la ayuda al desarrollo que junto al cercano $30 \%$ gestionado por el Ministerio de Economía y Hacienda constituyen, la suma de ambos, un elevadísimo $75 \%$ del total de la ayuda, cantidades ambas que contrastan nítidamente con el 15\% gestionado por el Ministerio de Asuntos Exteriores.

Por otro, en función de los volúmenes de los porcentajes consagrados a los préstamos FAD frente a las otras ayudas no reembolsables. Como puede observarse en los siguientes datos suministrados por la OCDE, tras un primer estadio de inestabilidad (1981/1987), a partir de 1988 los créditos FAD se convierten, no sólo en el programa pionero, dado que, como hemos acabado de ver, son creados en 1976, sino en el programa estrella de todos los llevados a cabo posteriormente en relación a su volumen, alcanzando su cenit a lo largo de los noventa cuyos porcentajes duplican con creces los dedicados a las ayudas no reembolsables.

Pero la importancia de este tipo de créditos no sólo reside en su volumen, sino también, y probablemente más significativo aún, en las operaciones realizadas con ellos, no sólo en cuanto a su discutida selección de países, no sólo en cuanto a los sectores que promociona, sino, y lo que es peor aún, a la vulneración más incuestionable de toda política de cooperación para el desarrollo: la venta de material militar.

Respecto al primero de los puntos, que constituye de hecho una singularidad más de la política de cooperación realizada, los países beneficiados por estos créditos, durante el período 1977/1995 y según datos del Instituto de Crédito Oficial, han sido: China, México, Marrue- 


$\begin{array}{ccc}\text { Año } & \text { \% no reembolsable } & \text { \% préstamos FAD } \\ 1981 & 35^{\prime} 1 \% & 51^{\prime} 4 \% \\ 1982 & 27^{\prime} 0 \% & 43^{\prime} 4 \% \\ 1983 & 57^{\prime} 7 \% & 21^{\prime} 1 \% \\ 1984 & 39^{\prime} 5 \% & 36^{\prime} 1 \% \\ 1985 & 31^{\prime} 3 \% & 44^{\prime}, 9 \% \\ 1986 & 25^{\prime} 6 \% & 3^{\prime} 4 \% \\ 1987 & 36^{\prime} 6 \% & 1^{\prime}, 0 \% \\ 1988 & 31^{\prime} 0 \% & 32^{\prime}, 6 \% \\ 1989 & 22^{\prime} 5 \% & 26^{\prime} 4 \% \\ 1990 & 23^{\prime} 5 \% & 42^{\prime}, 1 \% \\ 1991 & 19^{\prime} 2 \% & 41^{\prime} 0 \% \\ 1992 & 16^{\prime} 4 \% & 55^{\prime}, 9 \% \\ 1993 & 14^{\prime} 5 \% & 57^{\prime} 2 \% \\ 1994 & 19^{\prime} 6 \% & 45^{\prime}, 8 \%\end{array}$

Fuente: OCDE.

cos, Argentina, Ecuador y Argelia, que suman el 51'40\% de las concesiones procedentes de los créditos $\mathrm{FAD}$, el resto es repartido entre más de 30 países. La concentración de los créditos en estos seis países responde, según el informe del $\mathrm{CAD}^{16}$, a variables como solvencia económica o viabilidad financiera, aplicadas, paradójicamente, a países con ingresos medio/altos, no viéndose beneficiados los Estados realmente necesitados ${ }^{17}$ de esta modalidad de créditos.

En segundo lugar, y según las Líneas Directrices establecidas en 1987 por el Consejo de Ministros, los sectores prioritarios a favorecer con estos capitales deberían ser: la agricultura, la sanidad, la formación profesional, el reforzamiento de las instituciones, entre otros. Pues bien, en la práctica la distribución ha sido bien distinta. Frente al $17^{\prime} 6 \%$ que los miembros del CAD destinaron a comienzos de los años noventa a infraestructura económica (transporte, comunicaciones, energía, etc.), nuestro país, por medio de los créditos $\mathrm{FAD}$, consagró nada menos que un $48^{\circ} 0 \%$. Las siguientes cifras, tomadas de otros sectores relevantes, destacan, nuevamente, la naturaleza de la instrumentalización económica y comercial de los FAD españoles:

$\begin{array}{lll} & \text { España } & \text { CAD } \\ \text { Servicio educativo } & 4,9 \% & 9^{\prime} 2 \% \\ \text { Agricultura } & 0^{\prime} 9 \% & 7^{\prime} 1 \% \\ \text { Industria, minería... } & 14^{\prime}, 8 \% & 3^{\prime}, 3 \% \\ \text { Manufacturas } & 10^{\prime}, 7 \% & 1,9 \% \\ \text { Ayuda alimentaria } & 0^{\prime}, 9 \% & 3,2 \% \\ \text { Ayuda de emergencia } & 0^{\prime} 5 \% & 3,3 \% \\ \text { Reorganización deuda } & - & 18^{\prime} 1 \%\end{array}$

Fuente: OCDE.

16 Primer examen elaborado por el CAD sobre la ayuda española y su política de cooperación para el desarrollo, 29 de abril de 1994.

17 Entre los seleccionados, no se encuentra ni uno sólo de los considerados por las Nacio- 
No es de sorprender, pues, que el informe del CAD terminara sugiriendo la necesidad de una modificación de los textos que regulan el FAD, ya que desde su creación éste no ha sido concebido como un instrumento de ayuda, siendo indispensable, por consiguiente, «trazar nítidamente la frontera entre la ayuda y los intereses comerciales». Estimo oportuno recoger en estas páginas la posición de la patronal CEOE, en opinión de la cual hay que «concebir la AOD cubriendo el doble objetivo, tanto de ayuda a los pueblos menos favorecidos como de atender a las necesidades de la sociedad española... En este sentido, se considera que no debe existir una incompatibilidad entre la AOD y la creación de empleo y la proyección exterior de nuestra capacidad económica e industrial a nivel internacional $\gg^{18}$. Es obvio que el problema de nuestra política de cooperación para el desarrollo no versa únicamente sobre una cuestión de volumen, sino también de significado y naturaleza.

Y a propósito de significado y naturaleza, la vulneración más flagrante de la misma, independientemente de que pueda o no existir incompatibilidad entre ambas finalidades (lo que sí existe en materia de cooperación para el desarrollo son prioridades), la encontramos, desgraciadamente, en una operación comercial no ya «meramente» incompatible, sino en las antípodas, inexistente, en toda política que se tercie para el desarrollo: la venta de material militar. La ausencia de información detallada sobre lo que ha venido siendo nuestra política de cooperación (exigida por el Congreso de los Diputados y el Senado en los documentos ya mencionados, criticada por el informe del CAD, reconocida por el Tribunal de Cuentas, y admitida, incluso, en la nueva Ley de $1998^{19}$ ) impide un conocimiento exhaustivo de los destinos de ciertas partidas presupuestarias, pero a pesar de las negaciones sucesivas de los responsables gubernamentales, por vez primera, en el Boletín del Senado núm. 196, pág. 55 de 1994 se reconoce la utilización de 42.893 millones, saltando desde entonces por los aires todas las sospechas existentes, las cuales pueden ser resumidas de la manera siguiente: la utilización de estos créditos para financiar exportaciones ligadas a

nes Unidas como país menos desarrollado (PMA). Lógicamente, las autoridades españolas han venido justificándose argumentando que las ayudas económicas hacia estos países ya se canalizan a través de la ayuda multilateral.

18 La Cooperación al Desarrollo. Informe 1995. Fundación de Cooperación para el Desarrollo en infraestructuras, medio ambiente, equipamientos y servicios. Madrid, 1996. págs. 311 y 312 .

19 «Al mismo tiempo, la Ley de Cooperación no puede eludir los problemas que presenta el marco actual: rigidez excesiva en los procedimientos administrativos, necesidad de una mayor transparencia...». Apartado II, Estado actual de la cooperación, Ley 23/ 1998, de 7 de julio. 
la defensa y al armamento han constituido una práctica habitual.

Un balance desapasionado de la ayuda española al desarrollo no puede prescindir, pues, de unas críticas argumentadas y justificadas que clarifican el prisma por el que se aborda el conocimiento. No puede eludirse que, junto al necesario reconocimiento de los esfuerzos realizados que han aproximado notablemente nuestra ayuda a la cooperación al modelo de los países miembros del CAD, han existido no sólo insuficiencias e instrumentalización comercial, tampoco por ello debe caerse en la ingenuidad de estigmatizar el caso español, sino también vulneración de los principios más elementales que inspiran a cualesquiera de las políticas a aplicar. Y, por supuesto, tampoco debemos escudar nuestros errores en el retraso y en la inexperiencia.

\section{LA LEY DE 1998, UN HITO EN LA HISTORIA DE LA POLÍ- TICA ESPAÑOLA PARA LA COOPERACIÓN AL DESA- RROLLO.}

\subsection{Una ligera endoscopia de los aspectos más relevantes intro- ducidos por la nueva Ley.}

Felizmente, una de las promesas políticas incumplidas ha llegado a buen puerto tras superar ciertos avatares que alarmaron a la oposición parlamentaria y a la Plataforma 0'7 en la cámara del Senado. Tras su devolución al Congreso de los Diputados, la satisfacción del resultado final es un rasgo que, en gran medida, caracteriza este nuevo estadio en el que penetra la cooperación española.

En mi opinión, el enunciado más importante y esperanzador para la evolución futura de nuestra cooperación al desarrollo, tras los argumentos expuestos en páginas precedentes, se recoge en el artículo 1 de la sección $1 .^{a}$ del capítulo I, según el cual: «para que dichos recursos tengan la consideración de Ayuda Oficial al Desarrollo (AOD), deberán cumplir los requisitos marcados por el Comité de Ayuda al Desarrollo de la OCDE (CAD)» ${ }^{20}$.

Es decir, la ayuda debe regirse por principios éticos, por lo que deben ser las demandas de los beneficiarios, y no los intereses o conveniencias de los donantes, las que deben inspirar la ayuda. Esto no supone, como en principio puede parecer, un «jaque-mate» a los créditos bilaterales reembolsables de la ayuda ligada (créditos FAD), pero sí,

20 Es relevante subrayar que este enunciado no aparecía en el inicial proyecto de ley gubernamental. 
puede y debe ser interpretado, y ahora con peso jurídico, un control más exhaustivo sobre su utilización, tanto sobre el volumen como sobre su destino y significado.

Es importante subrayar igualmente de este mismo artículo la incorporación (también inexistente en el proyecto gubernamental) de objetivos más precisos que deben delimitar toda acción en política de cooperación internacional para el desarrollo, ejecutándose éstos con el fin de:

1. facilitar e impulsar el progreso económico y social de los países en vías de desarrollo,

2. contribuir a la erradicación de la pobreza en el mundo en todas sus manifestaciones,

3. defender y proteger los derechos humanos y las libertades fundamentales, las necesidades de bienestar económico y social y su inserción en la economía internacional,

4. contribuir a la consolidación plena de sus instituciones democráticas y regeneración del medio ambiente.

En segundo lugar, y en relación con los objetivos establecidos, la política española de cooperación para el desarrollo debe inspirarse en los siguientes principios:

1. el reconocimiento del ser humano en su dimensión individual y colectiva,

2. la defensa y promoción de los derechos humanos y la libertades fundamentales, la paz, la democracia y la participación ciudadana, incluyendo además como novedad: «en condiciones de igualdad para mujeres y hombres y, en general, la no discriminación por razón de sexo, raza, cultura o religión, y el respeto a la diversidad».

3. Asimismo ha sido incorporado otro enunciado relevante, indispensable como principio inspirador de este modelo de políticas: «la promoción de un crecimiento duradero y sostenible de los países acompañada de medidas que promuevan una redistribución equitativa de la riqueza para favorecer la mejora de las condiciones de vida y el acceso a los servicios sanitarios, educativos y culturales, así como el bienestar de la poblaciones».

El tercer aspecto relevante a tener en cuenta de esta nueva ley reside en el papel a desempeñar por la denominada cooperación descentralizada, que ciertamente ha venido ya desarrollando en los últimos años, o sea, la llevada por las ONGD, Comunidades Autónomas y Corporaciones Locales.

Quedan recogidos en la Ley tanto el compromiso por parte del Esta- 
do para el fomento de las actividades llevadas a cabo por las ONGD como los requisitos que éstas deben cumplir para acceder a las ayudas y subvenciones, inscripción en el registro y el régimen fiscal que les atañe. Es interesante tener en consideración la supresión del proyecto de ley de la expresión «entidades de reconocido prestigio» a la hora de determinar los criterios que las definen. Como ya señalé en la comunicación presentada en el Congreso de Málaga, para el grupo parlamentario popular, la eliminación de esta expresión dejaría fuera a todas aquellas fundaciones, organizaciones, asociaciones e instituciones que han trabajado por la solidaridad. Pero a mi modo de ver esta expresión supone, por el contrario, no tomar en serio la labor de muchas ONGD de recién constitución que igualmente desempeñan sus labores en este ámbito. Ni qué decir tiene que han sido las organizaciones de naturaleza religiosa las que han venido monopolizando y protagonizando sin interrupción la ayuda a la solidaridad, por lo que la supresión de esta expresión no sólo no excluye, sino que incluye a todas las ONGD, religiosas, aconfesionales y las vinculadas a partidos políticos y sindicatos.

\subsection{Un breve balance de la política de cooperación de los últi- mos años.}

En los últimos años hemos sido testigos de notables cambios producidos tanto en el volumen como en la calidad de nuestra Ayuda Oficial al Desarrollo.

En 1998, el presupuesto destinado para este fin, en miles de millones de pesetas, ha logrado alcanzar un nuevo techo presupuestario, 214.256, de los cuales 131.882 son destinados a la ayuda bilateral y los 82.374 restantes a la ayuda multilateral (61' $55 \%$ y $38^{\prime} 45 \%$ de la AOD respectivamente). Queda por ver si las previsiones finales se cumplen este año y se logra mantener el extraordinario resultado de 1997, superando por primera vez la media ponderada de los países de la OCDE (0'23 frente al 0'22).

$\begin{array}{llc}\text { Año } & \text { España } & \text { Media de países OCDE } \\ 1993 & 0^{\prime} 28 \% & 0^{\prime} 30 \% \\ 1994 & 0^{\prime} 28 \% & 0^{\prime} 30 \% \\ 1995 & 0^{\prime} 24 \% & 0^{\prime} 27 \% \\ 1996 & 0^{\prime} 22 & 0^{\prime} 25 \\ 1997 & 0^{\prime} 23 & 0^{\prime} 22 \\ 1998 & 0^{\prime} 26 \text { (prev.) } & -\end{array}$

Fuente: PACIS Previsiones y Seguimientos y CAD-OCDE. En porcentajes del PNB.

Respecto al tipo de ayuda bilateral, las modificaciones han reconducido substancialmente el modelo de nuestra cooperación, procediéndose en 1995 a una caída notable de las ayudas de tipos re- 
embolsables, pero no en beneficio directo a las ayudas no reembolsables, las cuales han seguido creciendo en cuanto a volumen neto ciertamente, sino más bien de las inversiones adjudicadas a la ayuda multilateral, pasando éstas de 45.999 miles de millones de pesetas en 1996 a 68.714 en 1997 y 82.374 este año $\left(28^{\prime} 73,38^{\prime} 02\right.$ y $38^{\prime} 45 \%$ de la AOD respectivamente).

$\begin{array}{lcccc}\text { Año } & \text { Reembolsable } & \% & \text { No reembolsable } & \% \\ 1993 & 94.926 & 57^{\prime} 24 & 24.003 & 14^{\prime} 47 \\ 1994 & 80.021 & 45^{\prime}, 56 & 35.169 & 20^{\prime} 02 \\ 1995 & 35.292 & 20^{\prime}, 99 & 66.255 & 39^{\prime} 41 \\ 1996 & 41.184 & 25^{\prime}, 72 & 72.924 & 45^{\prime} 55 \\ 1997 & 33.022 & 18^{\prime} 27 & 79.004 & 43^{\prime}, 71 \\ 1998 & 40.651 & 18^{\prime}, 97 & 91.231 & 42^{\prime} 58\end{array}$

Fuente: PACIS Previsiones y Seguimientos y CAD-OCDE.

Por distribución geográfica, las áreas beneficiadas por la ayuda española no han sido alteradas considerablemente. Desde los años noventa, América Latina ha sido la principal receptora de nuestra ayuda, con el $37 \%$ de los presupuestos de este año sigue manteniéndose en cabeza, seguida por Africa Subsahariana con el $25 \%$, norte de Africa $10 \%$ y Oriente Próximo un 4\%.

Este panorama que ha implicado una nueva distribución de los escasos recursos a disposición de la ayuda al desarrollo junto con la aprobación de la ley para la cooperación internacional española dibujan un horizonte más halagüeño en el desarrollo y evolución futuros de nuestra cooperación. Asimismo, el papel importante que están desempeñando las numerosas ONGD, el aumento de la concienciación y sensibilidad ciudadana han impulsado el incremento de las ayudas y subvenciones que éstas perciben de la Administración Central del Estado ${ }^{21}$. Como es común anhelar en todo Estado de Derecho, sólo nos queda aguardar ahora que la Ley se cumpla.

\section{CONCLUSIONES.}

La política española para la cooperación al desarrollo ha adolecido, ciertamente, de graves insuficiencias y recursos, los cuales, en cierto modo, han ensombrecido los incuestionables esfuerzos realizados a lo largo de estas dos décadas. Como acontece con nuestro Estado de Bienestar, las críticas, aunque reconociendo simultáneamente los logros alcanzados igualmente en esta materia, se centran en el modelo 
ortopédico de nuestro poco desarrollado sistema público de servicios sociales, las exiguas medidas de política social o la insufrible seguridad social, amparadas todas ellas en el abandono de nuestro país durante los grises años del interminable régimen franquista.

La impecable acción política por modernizar nuestro país y europeizar nuestros hábitos, cuya manifestación más sobrecogedora en el campo de la cooperación la encontramos en la proliferación de organizaciones decididas a participar activamente en este ámbito, ha originado un revival del boom asociativo tras la recuperación de las libertades. Afanosamente, acciones como las llevadas a cabo por la Plataforma 0'7 nos han conducido a tomar conciencia de la sensibilización que despierta en nuestra sociedad civil la miseria y las injusticias que padecen ingentes ejércitos de miserables de los denominados Tercer y Cuarto mundo. La generosidad de la sociedad española, expresada en las encuestas publicadas manifestando abiertamente su apoyo y solidaridad hacia los pueblos de la tierra más desfavorecidos, exige el diseño de una política más coherente con los principios inspiradores que configura toda cooperación para el desarrollo. Los contextos económicos, en gran medida, con sus retraimientos poco favorecedores a políticas más expansionistas y ambiciosas, permiten justamente, por su parte, tener siempre en consideración, que en momentos económicos poco propicios a elevadas inversiones públicas, se ha edificado sobre nuestro país un ámbito político prácticamente desconocido por el caduco régimen anterior, así como un insuficiente Estado Social que goza aún de gran apoyo por una amplia mayoría de nuestra ciudadanía. Es interesante destacar como Estado de bienestar y política de cooperación para el desarrollo caminan paralelamente unidos gracias a un sólido pivote sobre el que se sostiene toda la razón de ser de la convivencia en estos modelos de organización política: la ciudadanía social. No en vano, y tampoco es de extrañar, que el welfare escandinavo, convertido en modelo paradigmático por los científicos sociales, lo sea a su vez en política de cooperación para el desarrollo. El arraigado concepto de la ciudadanía en esos lares ha promovido una participación activa en todos los campos y materias, junto con una acción decidida y comprometida por sus respectivas autoridades políticas consolidadas sobre un elemento de cultura política envidiable: el consenso. Noruega, Dinamarca, Suecia están a la cabe$\mathrm{za}$, a pesar de las vicisitudes económicas, de los modelos de gran cohesión social y apoyo político y ciudadano hacia las medidas de cooperación con los países en vías de desarrollo.

La aprobación por las Cortes Generales de una ley de estas características obedece, pues y para concluir, a una deuda pendiente del poder político con todos aquellos, miles de hombres y mujeres, que entregan gratuitamente parte de su tiempo y su ilusión, algunos desgraciada- 
mente incluso sus vidas, al servicio de los más desfavorecidos en aras de la justicia social.

\section{BIBLIOGRAFÍA}

Efforts et Politiques des Membres du Comité d'Aide au Développement, Coopération pour le Développement, OCDE-CAD, Rapport 1997, París, 1998.

Manual de la Ayuda al Desarrollo. Principios del CAD para una ayuda eficaz. Coedición Organización de Cooperación y Desarrollos Económicos, Ediciones Mundi-Prensa, París, 1995.

MARTÍNEZ TABLAS, A. (coord): Visión global de la cooperación para el desarrollo. Centro de Investigación para la paz, Icaria Editorial, Madrid, 1995.

Nuevas perspectivas en la política de cooperación al desarrollo en la Unión Europea, Agencia Española de Cooperación Internacional, Madrid, 1996.

PÉREZ SOBA, I.: La juventud española y la cooperación para el desarrollo. varias entidades colaboradoras, Madrid, 1996.

VV.AA.: La cooperación internacional para el desarrollo: ámbito y configuración. CIDEAL, Madrid, 1994.

VV.AA.: Nuevas tendencias en la cooperación internacional. CIDEAL, Madrid, 1994.

The Reality of Aid, An Independet Review of Poverty Reduction and Development Assistance 1989/1999, Earthscan, London, 1998. 